\title{
DIFICULTADES QUE SE PRESENTAN EN COLOMBIA ALREDEDOR DE LA PÓLIZA DE SEGURO DE RESPONSABILIDAD CIVIL*
}

\section{PROBLEMS AND DIFFICULTIES THAT ARISE AROUND THE LIABILITY INSURANCE IN COLOMBIA}

María Cristina Isaza Posse**

Fecha de recepción: 30 de junio de 2016

Fecha de Aceptación: 16 de junio de 2016

Disponible en línea: 30 de Julio de 2016

\section{Para Citar este articulo/To cite this article}

Isaza Posse, María Cristina, Dificultades que se presentan en Colombia alrededor de la Póliza de seguros de responsabilidad Civil, 44 Rev.Ibero-Latinoam.Seguros, 141-172 (2016). http://dx.doi.org/ 10.11144/Javeriana.ris44.dpcp doi:10.11144/Javeriana.ris44.dpcp

* Artículo de Reflexión

** Abogada Universidad Javeriana. Especialista y Magistra en Derecho de Seguros, Universidad Javeriana. Asesora y Consultora. Profesora Universitaria. Contacto: mcisaza@isazaposse.com 


\section{RESUMEN}

Varios aspectos relacionados con la cobertura otorgada bajo las pólizas de seguro de responsabilidad civil merecen una revisión cuidadosa por parte del sector asegurador colombiano, del cual hacen parte las aseguradoras, tomadores, asegurados y beneficiarios, intermediarios de seguros, asociaciones gremiales y las entidades que tienen a su cargo la vigilancia y control de la actividad.

Se pretende que mediante el estudio y análisis de los problemas y dificultades que se presentan alrededor de esta clase de seguro, encontremos soluciones que permitan obtener resultados que redunden en beneficio de quienes participan en el sector, facilitando a su vez, que el seguro cumpla con la función de protección y salvaguarda patrimonial que le es propia.

Se aborda el tema desde los siguientes aspectos: Cobertura para perjuicios extrapatrimoniales, Exclusión de la culpa grave del asegurado; Tesis de responsabilidad directa de la entidad asegurada en los casos del dolo del dependiente. Transferencia del dolo del dependiente a la persona jurídica asegurada; Modalidades de delimitación temporal de la cobertura; Prescripción de las acciones del seguro en las tres modalidades de delimitación temporal de la cobertura; Término de prescripción de la acción de responsabilidad civil extracontractual; Otorgamiento de la cobertura de RC Patronal en exceso de las prestaciones de la seguridad social; Exigencia de que el hecho generador del daño sea accidental, súbito e imprevisto; Cláusula compromisoria o de arbitramento; Sublímites bajos en coberturas distintas del límite establecido para el amparo básico; Necesidad de probar la responsabilidad del asegurado en los casos en que la ley establece procedimientos especiales, cuando se ejerce la acción directa contra la aseguradora; Gastos de defensa. Momento a partir del cual es exigible la obligación de la aseguradora.

Palabras clave: Contrato de seguro; Seguro de responsabilidad civil. 


\begin{abstract}
It is intended that through the study and analysis of the problems and difficulties that arise around this type of insurance, we find solutions that benefit those involved in the sector; facilitating in turn that the insurance meets the function of protecting and safeguarding assets.

The issue is addressed considering the following: Coverage for non-pecuniary damages. Exclusion from gross negligence of the insured. Thesis of direct responsibility of the insured in cases of fraud of the dependent. Transference of the intent of the insured to the dependent legal person. Types of temporary delimitation of coverage. Limitation of actions of insurance in all three types of temporary delimitation of coverage. Term of limitation for tort action. Granting RC Patronal coverage in excess of social security benefits. Requirement that the relevant event is accidental, sudden and unexpected. Arbitration or arbitration clause. Low sub-limits when a different coverage limit is established for basic protection. Need to prove the liability of the insured in cases where the law establishes special procedures, when direct action against the insurer is exercised. Defense spending. Moment from which is enforceable the obligation of the insurer.
\end{abstract}

KEYWORDS: Insurance agreement; insurance policy; Liability insurance.

\title{
SUMARIO
}

INTRODUCCIÓN. 1.Cobertura para perjuicios extrapatrimoniales. 2. Exclusión de la culpa grave del asegurado. 3. Tesis de responsabilidad directa de la entidad asegurada en los casos del dolo del dependiente. Transferencia del dolo del dependiente a la persona jurídica asegurada. 4. Modalidad de delimitación temporal de la cobertura. 5. Prescripción de las acciones del seguro en las tres modalidades de delimitación temporal de la cobertura. 6 . Término de prescripción de la acción de responsabilidad civil extracontractual. 7. Otorgamiento de la cobertura de RC Patronal en exceso de las prestaciones de la seguridad social. 8. Exigencia de que el hecho generador del daño sea accidental, súbito e imprevisto. 9. Cláusula compromisoria o de arbitramento. 10. Sublímites bajos en coberturas distintas del límite establecido para el amparo básico. 11. Necesidad de probar la responsabilidad del asegurado en los casos en que la ley establece procedimientos especiales, cuando se ejerce la acción directa contra la aseguradora. 12. Gastos de defensa. Momento a partir del cual es exigible la obligación de la aseguradora. REFERENCIAS. 


\section{INTRODUCCIÓN}

Los siguientes aspectos relacionados con la cobertura otorgada bajo las pólizas de seguro de responsabilidad civil en el mercado asegurador colombiano merecen una revisión cuidadosa por parte del sector, del cual hacen parte las aseguradoras, tomadores, asegurados y beneficiarios, intermediarios de seguros, asociaciones gremiales y las entidades que tienen a su cargo la vigilancia y control de la actividad.

La finalidad buscada con el señalamiento de los aspectos que generan dificultades en cuanto se refiere al seguro de responsabilidad civil es de naturaleza constructiva. Se pretende que mediante el estudio y análisis de los problemas y dificultades que se presentan alrededor de esta clase de seguro, encontremos soluciones que permitan obtener resultados que redunden en beneficio de quienes participan en el sector asegurador, facilitando a su vez, que el seguro cumpla con la función de protección y salvaguarda patrimonial que le es propia.

1. Cobertura para perjuicios extrapatrimoniales

Mediante la reforma introducida en Colombia al régimen del contrato de seguro de responsabilidad civil por la Ley 45 de 1990, se modificó el texto del artículo 1127 del Código de Comercio.

El artículo anterior establecía:

"El seguro de responsabilidad impone a cargo del asegurador la obligación de indemnizar los perjuicios patrimoniales que sufra el asegurado con motivo de determinada responsabilidad en que incurra de acuerdo con la ley. Son asegurables la responsabilidad contractual y la extracontractual con la restricción indicada en el artículo 1055 "

El artículo modificado y hoy vigente dispone:

"Artículo 1.127 - El seguro de responsabilidad impone a cargo del asegurador la obligación de indemnizar los perjuicios patrimoniales que cause el asegurado con motivo de determinada responsabilidad en que incurra de acuerdo con la ley y tiene como propósito el resarcimiento de la víctima, la cual en tal virtud, se constituye en el beneficiario de la indemnización, sin perjuicio de las prestaciones que se le reconozcan al asegurado. 
Son asegurables, la responsabilidad contractual y la extracontractual, al igual que la culpa grave, con la restricción indicada en el Art. 1055"

De acuerdo con la redacción de la norma vigente, el objeto del seguro de responsabilidad civil es otorgar cobertura para la indemnización de los perjuicios patrimoniales que cause el asegurado por los cuales resulte civilmente responsable. Y cabe preguntar: ¿dónde queda la cobertura de los perjuicios extrapatrimoniales que también causa el asegurado?

Si la definición del amparo otorgado se encuentra redactado en la póliza en los mismos términos del artículo 1127 del Código de Comercio, resultaría forzoso concluir que la indemnización que corresponda a los perjuicios extrapatrimoniales no se encuentra dentro de la cobertura. En consecuencia, no hacen parte de la obligación a cargo de la aseguradora, pero ello no implica que el asegurado causante del daño y responsable quede exonerado de su obligación de responsabilidad frente a la víctima.

La obligación de responder plenamente por los perjuicios causados, se traduce en un deber de pagar una indemnización a cargo del causante del daño. Los perjuicios que se causen y que deben ser indemnizados de manera plena, son tanto los patrimoniales, como los extrapatrimoniales. Al dejar por fuera de la cobertura que se otorga mediante el seguro los perjuicios extrapatrimoniales, entre los que se encuentra el daño moral, el daño a la vida de relación o alteración de condiciones de existencia y la vulneración de los derechos constitucionalmente tutelados, se está dejando parcialmente desprotegido al asegurado.

La finalidad buscada por el asegurado al suscribir una póliza de esta naturaleza es la de proteger su patrimonio en el evento de que se vea obligado a responder por un daño causado a un tercero, sin que para él resulte relevante el carácter patrimonial o no, del perjuicio sufrido por la víctima. En ocasiones, la totalidad de la indemnización que debe pagar el asegurado está compuesta por perjuicios de naturaleza extrapatrimonial, los cuales se encuentran sin cobertura, bien sea porque se encuentran expresamente excluidos en las condiciones de la póliza, o porque el Amparo otorgado se encuentra redactado en los mismos términos del artículo 1127 del Código de Comercio. 
En un caso en el que el amparo otorgado por la póliza de seguro se limitaba a los perjuicios patrimoniales que causare el asegurado, la jurisprudencia de la Corte Suprema de Justicia dijo en cuanto se refiere a este aspecto:

"3.- Bajo tales supuestos y dado que en conjunto y coherentemente los tres cargos planteados tienen por objeto establecer, el primer término, cuál es el contenido de la expresión "perjuicios patrimoniales" empleada por el artículo 1127 del Código de Comercio y en segundo lugar, bajo esa definición qué alcances tienen los contratos de seguro de responsabilidad suscritos con las citadas compañías, ningún óbice representa que se ofrezca una respuesta simultánea a las censuras a examinar.

4.- En ese orden, ciertamente el artículo citado del código mercantil subrogado por el artículo 84 de la Ley 45 de 1990, señala que "El seguro de responsabilidad impone a cargo del asegurador la obligación de indemnizar los perjuicios patrimoniales que cause el asegurado con motivo de determinada responsabilidad en que incurra de acuerdo con la ley y tiene como propósito el resarcimiento de la víctima, la cual, en tal virtud, se constituye en el beneficiario de la indemnización sin perjuicio de las prestaciones que se le reconozcan al asegurado".

En atención a la naturaleza de este tipo de seguro es obvio que tendría por objetivo, como lo señala la Delegada del Ministerio Público proteger el patrimonio del asegurado por los daños que en el ejercicio de sus actividades cause a terceros, sobre todo porque en términos del artículo 2341 del Código Civil está obligado a indemnizar quien ha cometido un delito o culpa que ha inferido daño a otro, sin hacer distinción si éste es de carácter patrimonial o extrapatrimonial.

Por eso resultaba claro que con tal propósito el original artículo 1127 del Decreto Ley 410 de 1971 dispusiera que "el seguro de responsabilidad impone a cargo del asegurador la obligación de indemnizar los perjuicios patrimoniales que sufra el asegurado con motivo de determinada responsabilidad en que incurra de acuerdo con la ley".

Sin embargo aquella finalidad ya no resulta en la actualidad de la integralidad ideal en el sentido de proteger al asegurado por todos los perjuicios patrimoniales que sufra, toda vez que el artículo 84 de la Ley 45 de 1990 generó un cambio radical de modo que ahora la aseguradora no responde por todos los perjuicios patrimoniales que sufra el asegurado, sino por todos los perjuicios patrimoniales que éste le cause a terceros, lo cual significó a su vez un cambio de paradigma porque antes que proteger en esencia al asegurado se ampara a la víctima. 
La modificación de la norma al cambiar el verbo sufrir por causar, implica que las aseguradoras se obligan únicamente a indemnizar aquellos daños que el asegurado le genere a terceros, siempre y cuando sean del orden patrimonial, luego en principio cualquier agravio extrapatrimonial no es objeto de cobertura en este tipo de seguro, salvo desde luego que sea objeto de expresa estipulación contractual.

5.- Por eso resultan desacertadas ciertas consideraciones del casacionista y del Ministerio Público cuando aspiran a que las llamadas en garantía paguen por los terceros civilmente responsables o les reembolsen aquellas sumas erogadas por el asegurado o por las que fue condenado por concepto de cualquier clase de daño porque si bien el tercero víctima puede padecer un perjuicio extrapatrimonial que afecta obviamente el patrimonio del asegurado quien paga, la aseguradora se obliga, de lege lata, sólo a cubrir la lesión patrimonial que el asegurado le cause a la víctima y no las que él sufra, con lo cual en últimas y salvo convenio en contrario, la finalidad del citado pacto resulta un tanto desvirtuada.

Por el contrato de seguro de responsabilidad entonces y de conformidad con la normatividad que hoy nos rige, la aseguradora sólo está obligada a responder por los perjuicios patrimoniales que el asegurado le cause a la víctima y no por los perjuicios de esa naturaleza que sufra con ocasión de un delito o culpa contra terceros.

No es cierto que tanto en ese orden lo aducido por el casacionista acerca de que con el concepto "perjuicios patrimoniales" quiso la ley indicar que en el seguro de responsabilidad se imponía la obligación el asegurador, a modo de regla general, indemnizar todos los perjuicios causados al asegurado, o que todos los perjuicios padecidos por la víctima, patrimoniales o extrapatrimoniales, deben ser indemnizados por las aseguradoras en tanto ellos inciden finalmente en el patrimonio del asegurado, porque se repite si bien esto suele acontecer, la obligación de la aseguradora se restringe sólo a los daños patrimoniales causados por el asegurado al tercero y no los sufridos por el mismo con ocasión de cualquier tipo de perjuicio producido a la víctima.

Ese es el efecto introducido por la Ley 45 de 1990 al cambiar los términos en que definió el seguro de responsabilidad.

$\mathrm{Al}$ respecto la jurisprudencia civil señala:

"En ese caso se trataría de dejar a salvo el patrimonio del asegurado, pero no por los daños que reciba, sino por los que causa, en el entendido, al decir de la Sala, que además de procurar la reparación del daño 
padecido por la víctima, concediéndole los beneficios derivados del contrato, igualmente protege, así sea refleja o indirectamente la indemnidad patrimonial del asegurado responsable, en cuanto el asegurador asume el compromiso de indemnizar los daños provocados por éste, al incurrir en responsabilidad, dejando ilesa su integridad patrimonial, cuya preservación, en estrictez, es que anima al eventual responsable a contratar voluntariamente un seguro de esta modalidad "(....)" (CSJ SC,5 de jul. 2012 Rad. 2005-00425-01).

6.- Pero además de que la aseguradora sólo está obligada legalmente a pagar los perjuicios que el asegurado le cause al ofendido y no todos los que aquél padezca con ocasión de determinada responsabilidad en que incurra de acuerdo con la ley, como es el caso precisamente del tercero civilmente responsable, el ordenamiento la compele al pago no de cualquier clase de perjuicio causado a la víctima sino exclusivamente los de orden patrimonial, valga decir aquellos ocasionados a bienes o efectos de índole meramente económica y en ese sentido sólo responde en principio por el daño emergente, el lucro cesante y los daños morales objetivados, no así por los perjuicios morales subjetivo, ni los fisiológicos o daño de la vida en relación.

Por demás así lo determinó la Sala en sentencia del 12 de diciembre de 2005, Rad. No.24011 al señalar:

"La ley penal consagra dos clases de daños: i) los materiales que están integrados por el daño emergente y el lucro cesante y ii) los morales a su vez divididos en objetivados y subjetivados. Los primeros son de contenido patrimonial, mientras que los segundos afectan a la persona en esferas distintas a aquel.

“... las exigencias para la demostración y liquidación del daño se predican del perjuicio material, dejando al Juez la facultad de fijar los no valorables pecuniariamente que son los morales de carácter subjetivado en razón a que afectan el fuero interno de las víctimas o perjudicados, ya que se traducen en la tristeza, el dolor, la congoja o la aflicción que sienten las personas como consecuencia directa e inmediata del delito, cuyo único límite está determinado por la ley a partir de factores relacionados con la naturaleza de la conducta y la magnitud del daño causado"." 1

1 Sentencia Corte Suprema de Justicia. Sala de Casación Penal. SP13288-2014. Octubre $1^{\circ}$ de 2014. Radicación No.43575. magistrado ponente: Luis Guillermo Salazar Otero. 
2. Exclusión de la culpa grave del asegurado

En lo que se refiere al aseguramiento de la Culpa Grave bajo el seguro de responsabilidad civil, conviene precisar que la norma general en materia de riesgo asegurable, consagrada en el artículo 1056 del Código de Comercio, establece: "Con las restricciones legales, el asegurador podrá, a su arbitrio, asumir todos o algunos de los riesgos a que estén expuestos el interés o la cosa asegurados, el patrimonio o la persona del asegurado."

A su vez, el artículo 1055 del mismo código, dispone cuáles son los riesgos legalmente inasegurables. Dice el artículo: "El dolo, la culpa grave y los actos meramente potestativos del tomador, asegurado o beneficiario son inasegurables. Cualquier estipulación en contrario no producirá efecto alguno; tampoco lo producirá la que tenga por objeto amparar al asegurado contra las sanciones de carácter penal o policivo”. La sanción prevista por el legislador para el caso de que se incluya como riesgo alguno de estos previstos en la norma, es la ineficacia de la estipulación respectiva.

La reforma introducida por el artículo 84 de la Ley 45 de 1990 al artículo 1127 del Código de Comercio contiene una disposición especial para el seguro de responsabilidad civil. Establece el inciso segundo del mencionado artículo que "son asegurables la responsabilidad contractual y la extracontractual, al igual que la culpa grave, con la restricción indicada en el Art. 1055.

En la exposición de motivos de la Ley 45 de $1990^{2}$ se dejó constancia expresa de la intención buscada por el legislador con la reforma, en los siguientes términos: "Complementando lo dicho atrás sobre este punto y acogiendo las más modernas tendencias en la materia, se introduce la posibilidad de que en el seguro de responsabilidad se ampare la culpa grave, al tiempo que se precisa el cómputo de los tiempos de prescripción."

En cuanto hace referencia a este aspecto, la Corte Suprema de Justicia se pronunció en sentencia de julio 9 de 2012, y dijo:

"Ahora bien, la norma a que se remite establece que "el dolo, la culpa grave y los actos meramente potestativos del tomador, asegurado o beneficiario son inasegurables", lo que podría llevar a pensar que existe una contradicción entre ambos preceptos, en el entendido

2 Título III. Capítulo III. PROTECCIÓN DE TOMADORES Y ASEGURADOS. 
de que precisamente el uno permite lo que el otro prohíbe, por lo que se hace necesario establecer sus alcances aplicando las normas de interpretación contempladas en el artículo 25 y siguientes del Código Civil, además de la Ley 153 de 1887.

Al respecto la Sala, en sentencia de 8 de septiembre de 2011, exp. 2000-04366, consideró que "[e]n cuanto a la contradicción normativa, es útil memorar que, toda norma jurídica contiene un supuesto fáctico a cuya verificación se conecta una consecuencia jurídica (...) En línea de principio, el sistema jurídico es coherente, consistente o congruente $y$, por ende, no presenta asimetrías, contradicciones, incoherencias o conflictos normativos. En veces, distintos preceptos disciplinan idéntica o análoga hipótesis fáctica y asignan consecuencias incompatibles, es decir, a la misma fattispecie singular y concreta, atribuyen disímiles efectos (...) La antinomia normativa, es la manifiesta contradicción, incompatibilidad e incoherencia entre normas jurídicas de igual o diferente categoría, una o diversa uniformidad, homogeneidad, heterogeneidad, generalidad o especialidad, bien absoluta o total, ora parcial o relativa, ya en abstracto o en concreto, cuya solución se disipa con la interpretación sistemática, adecuada, ponderada, la técnica del equilibrio, la disociación o, los criterios disciplinados por el ordenamiento jurídico (...) El criterio jerárquico, atiende la naturaleza formal de las normas y su grado de autoridad. Cuando el conflicto verse sobre disposiciones de distinta categoría, se resolverá con la de rango mayor (lex superior derogat legem inferiorem; la ley superior deroga la ley inferior). Así, las normas constitucionales aplican de preferencia respecto de las disposiciones legales que las contradigan (artículo $4^{\circ}$ de la Constitución Política e inciso primero del artículo $5^{\circ}$ de la Ley 57 de 1887). El cronológico, está basado en la época de expedición de las normas, y resuelve el conflicto con la más reciente (lex posterior derogat priorem; la ley posterior deroga la ley anterior). Esta regla define las situaciones conflictivas generadas por tránsitos de legislación (artículos 1 a 3 de la Ley 153 de 1887). Empero, por su alto grado de objetividad, el legislador extiende sus alcances incluso a casos en los cuales las normas hacen parte de una misma ley o de un mismo Código, ad exemplum, según el numeral $2^{\circ}$ del artículo $5^{\circ}$ de la Ley 57 de 1887, dándose contradicción de dos normas del mismo estatuto, se preferirá la del 
artículo posterior. La especialidad, a diferencia, parte del contenido de la norma, y no de una cuestión formal, como la categoría, la fecha de promulgación, o el número del artículo que la identifica. Dependiendo del alcance de la norma en cuestión, el conflicto se resuelve a favor de la que tenga un mayor grado de concreción (lex specialis derogat generalem; la ley especial deroga la ley general), pero esta regla, dice autorizada opinión (Norberto Bobbio, Contribución a la Teoría del Derecho, Madrid, Debate, 1990, p. 344), es menos objetiva a las anteriores, por exigir previamente un trabajo hermenéutico definitorio del grado de generalidad o especialidad de las normas enfrentadas (...) La aplicación de las directrices hermenéuticas deviene problemática, pese a su claridad, cuando la antinomia se depura a favor de una norma según un criterio, y de otra, conforme a otro. Ejemplos de este tipo de problemas son los conflictos entre una norma anterior superior y una posterior inferior; entre una anterior especial frente a una posterior general; o cuando la primera es superior general y la segunda es inferior especial. Esta asimetría, en ciertos supuestos carece de respuesta uniforme u homogénea y los comentaristas remiten a las circunstancias especificas de cada uno (Bobbio, cit., pp. 350-353; María Teresa García-Berrio, 'Decálogo de las principales aportaciones de Norberto Bobbio al tratamiento de las antinomias', en Analisi e Diritto 2005, Torino, Giapichelli, 2006, pp. 189 y ss.) (...) La legislación colombiana, consagra directrices claras para solucionar las antinomias o contradicciones normativas. El artículo $5^{\circ}$ de la Ley 57 de 1987, modificado por los artículos $1^{\circ}$ a 48 de la Ley 153 de 1887, establece la metodología orientadora del juez y el intérprete para seleccionar cuál de las disposiciones jurídicas en conflicto debe aplicarse. Advertida incompatibilidad entre dos normas, el primer criterio hermenéutico aplicativo es el jerárquico, verbi gratia, la Constitución 'es ley reformatoria y derogatoria de la legislación preexistente', toda norma legal anterior claramente contraria a su letra o espiritu, 'se desechará como insubsistente'; en caso de incongruencia entre leyes, oposición de la anterior a la posterior o, tránsito de derecho antiguo a nuevo, la ulterior prevalece y aplica sobre la precedente, se considera insubsistente 'una disposición legal por declaración expresa del legislador, ó por incompatibilidad con disposiciones especiales posteriores, ó por existir una ley nueva 
que regula integramente la materia a que la anterior disposición se refería' (artículos $1^{\circ}, 2^{\circ}, 3^{\circ}$ y $9^{\circ}$ Ley 153 de 1887)".

En ese orden de ideas, aplicando los diferentes criterios, lo primero que se advierte es que los artículos 1055 y 1127 forman parte del mismo estatuto, esto es, el Código de Comercio contenido en el Decreto 410 de 1971, que cuando fue promulgado, en su orden, establecía:

"Artículo 1055. El dolo, la culpa grave y los actos meramente potestativos del tomador, asegurado o beneficiario son inasegurables. Cualquier estipulación en contrario no producirá efecto alguno, tampoco lo producirá la que tenga por objeto amparar al asegurado contra las sanciones de carácter penal o policivo".

"Artículo 1127. El seguro de responsabilidad impone a cargo del asegurador la obligación de indemnizar los perjuicios patrimoniales que sufra el asegurado con motivo de determinada responsabilidad en que incurra de acuerdo con la ley. Son asegurables la responsabilidad contractual y la extracontractual, con la restricción indicada en el Artículo 1055".

Vistos así, no se observa contradicción ni cosa diferente a que eran normas complementarias, coincidentes en cuanto a la imposibilidad de asegurar la culpa grave, so pena de que cualquier pacto en ese sentido quedaría viciado.

Sin embargo, la Ley 45 de 1990, por la cual se expidieron normas en materia de intermediación financiera y actividad aseguradora, en su artículo 84 modificó el 1127 del estatuto mercantil en los siguientes términos:

"El seguro de responsabilidad impone a cargo del asegurador la obligación de indemnizar los perjuicios patrimoniales que cause el asegurado con motivo de determinada responsabilidad en que incurra de acuerdo con la ley y tiene como propósito el resarcimiento de la víctima, la cual, en tal virtud, se constituye en el beneficiario de la indemnización, sin perjuicio de las prestaciones que se le reconozcan al asegurado (...) Son asegurables la responsabilidad contractual y la extracontractual, al igual que la culpa grave, con la restricción indicada en el artículo 1055".

De la confrontación entre la norma original y la que la reformó, se observa que la modificación se centró en esclarecer que los perjuicios a indemnizar eran los sufridos por la víctima, quien asume la 
calidad de beneficiario, así mismo que se hace asegurable la culpa grave.

A pesar de que se conservó la "restricción indicada en el artículo 1055 ", la misma no puede tener otro alcance que a los otros eventos contemplados en ella como son el "dolo (...) y los actos meramente potestativos del tomador".

Lo anterior en consideración a que, a pesar de que ambos artículos hacen parte de la misma codificación, el 1055 corresponde a una norma general dentro del capítulo "principios comunes a los seguros terrestres”, mientras que el 1127 es norma especial para el "seguro de responsabilidad", posterior dentro de la misma codificación y más reciente en su expedición, en consideración al cambio de que fue objeto.

En otros términos, luego de la modificación introducida, es claro que en el "seguro de responsabilidad" los riesgos derivados de la "culpa grave" son asegurables, y, por ende, su exclusión debe ser expresa en virtud a la libertad contractual del tomador, ya que de guardarse silencio se entiende cubierto." 3

En Colombia, la inclusión de la culpa grave como riesgo asegurado en el seguro de responsabilidad civil, se hace mediante pacto o estipulación expresa. Sin embargo es importante poner de presente que no es frecuente que las aseguradoras acepten incluirla dentro del riesgo asegurado. Sin embargo, compartimos la tesis de la Corte en el sentido de afirmar que si se otorga una cobertura general para los perjuicios derivados de la responsabilidad civil imputable al asegurado y no se encuentra expresamente excluida la culpa grave, ésta se encontraría incluida dentro del riesgo asegurado bajo el amparo otorgado.

3. Tesis de responsabilidad directa de la entidad asegurada en los casos del dolo del dependiente. Transferencia del dolo del dependiente a la persona jurídica asegurada

La jurisprudencia colombiana ha sostenido la tesis de la Responsabilidad Directa, resumida como sigue en sentencia de la Corte Suprema de Justicia:

3 Sentencia Corte Suprema de Justicia. Sala Civil. Julio 5 de 2012. Ref: Exp. 05001-3103-008-200500425-01. Magistrado ponente: Fernando Giraldo Gutiérrez. 
“a) En primer lugar, que la culpa personal de un agente dado, funcionario directivo o subalterno auxiliar, compromete de manera inmediata y directa a la persona jurídica cuyos intereses sirve, desde luego en cuanto de la conducta por el primero observada pueda aseverarse que hace parte del servicio orgánico de la segunda. En consecuencia, cuando un individuo -persona natural-incurre en un ilícito culposo, actuando en ejercicio de sus funciones o con ocasión de ellas, queriendo así por el ente colectivo, no se trata de una falta del encargado que por reflejo obliga a su patrón, sino una auténtica culpa propia imputable como tal a la persona jurídica, noción esta que campea en el panorama nacional (G.J. Tomo CXXII, pág. 214)..." 4

Como puede apreciarse con facilidad, la adopción de esta tesis trae como consecuencia que, la inasegurabilidad del dolo por expresa disposición legal y la exclusión tanto del dolo como de la culpa grave en las condiciones generales o particulares del contrato de seguro, resulten plenamente aplicables en los casos de responsabilidad del asegurado derivada del dolo o culpa grave del dependiente. Esto trae como resultado la inutilidad de las pólizas de seguro de responsabilidad civil suscritas por las personas jurídicas o naturales aseguradas en los casos en que ven comprometida su responsabilidad y resultan obligadas a responder por los daños causados de manera dolosa o gravemente culposa por sus dependientes.

La Corte Suprema de Justicia en sentencia de octubre de 2014, se pronunció exonerando a la aseguradora que había otorgado la cobertura mediante una póliza de seguro de responsabilidad civil médica que cubría la responsabilidad de la entidad asegurada, fundando su decisión en la tesis de la responsabilidad directa, en virtud de la cual el dolo del dependiente equivale al dolo de la entidad.

\section{Dijo la Corte:}

"Los medios de conocimiento practicados durante el incidente reparación integral (15), revelan que la aseguradora en cita, el 20 de septiembre de 2011, expidió a favor de la Clínica XXX la póliza No. 000 con el propósito de amparar la responsabilidad civil de ésta,

4 Citada en sentencia Corte Suprema de Justicia. Sala Penal. SP13285-2014. Octubre 1 de 2014. Radicación: 42256. Magistrado ponente: Fernando Alberto Castro Caballero. 
observándose que dentro de su clausulado se estableció, en la Sección II dedicada a las "exclusiones", que "1. En ningún caso están cubiertos los siniestros generados por o resultantes de: 1.1. Dolo o culpa grave del tomador, asegurado o beneficiario".

En concordancia con lo anterior, el artículo 1055 del Código de Comercio preceptúa que "el dolo, la culpa grave y los actos meramente potestativos del tomador, asegurado o beneficiario son inasegurables. Cualquier estipulación en contrario no producirá efecto alguno."

En el caso de la especie, se tiene que el daño causado fue producto de la acción dolosa del sentenciado XXXXXX, quien abusó sexualmente de NNN y AAA durante a consulta que como médico les realizó en las instalaciones de la Clínica XXX.

Así las cosas, es claro que por ministerio de la ley, amén de que en el contrato de seguro suscrito entre la Clínica XXX y Seguros XXX así se estipuló, no hay lugar a que esta última entre a indemnizar los daños en razón de la póliza que expidió.

En ese sentido, apunta igualmente a jurisprudencia de esta Sala (CSJ AP, 18 Abr. 2012, Rad. 37506) y la de la Sala Civil, pues, con claridad ésta última ha concluido:

El artículo 1055 del Código de Comercio, al cual remite el inciso final del 1127, contempla prohibitivamente la "inasegurabilidad" del dolo, de tal manera que "cualquier estipulación en contrario no producirá efecto alguno", lo que tiene su fundamente en la incertidumbre del suceso como uno de los elementos esenciales del "seguro" y en razones de orden público, toda vez que permitir la protección frente a la ocurrencia de hechos ilícitos derivados del tomador sería tanto como facilitar su comisión.

En esa dirección, indefectiblemente de su estipulación expresa, como ocurre en este caso, el establecimiento de que la responsabilidad origen del reclamo se deriva de un comportamiento doloso del asegurado, deja sin piso cualquier pretensión indemnizatoria frente a quien expide la garantía. (C. S.J. SC, 5 Jul. 2005, Rad. 05001-3103008-2005-00425-01).

En esa medida, no le asiste la razón a la fiscal Delegada ante esta Corporación, cuando concluye que Seguros XXX debe responder por los daños en el asunto que concita la atención, en tanto centra su afirmación en la simple existencia de la póliza mas no en su clausu- 
lado, desconociendo de paso con ello la exclusión legal prevista en el artículo 1055 del Código de Comercio." 5

4. Modalidad de delimitación temporal de la cobertura

Otro punto que merece especial atención es el relacionado con la modalidad temporal de la cobertura. A partir de la expedición de la Ley 389 de 1997, las pólizas de seguro de responsabilidad civil pueden pactarse en Colombia bajo tres modalidades: ${ }^{6}$ i) Ocurrencia, ii) Reclamación y iii) Ocurrencia de Cola Corta (Reclamación Especial, Sistema Mixto, Sunset):

Ocurrencia: Bajo esta modalidad, la aseguradora cubre el valor de la indemnización que tenga que pagar el asegurado como consecuencia de la responsabilidad civil derivada de hechos ocurridos durante la vigencia del seguro, sin tomar en consideración el momento en que se presente la reclamación, siempre y cuando dicha reclamación sea presentada dentro de los términos de prescripción establecidos por la ley para la acción de responsabilidad civil correspondiente.

Reclamación o Claims Made: bajo esta modalidad, la aseguradora cubre el valor de la indemnización que tenga que pagar el asegurado como consecuencia de la responsabilidad civil derivada de reclamaciones presentadas por la víctima al asegurado o a la aseguradora durante la vigencia del seguro. En esta clase de coberturas se establece, por norma general, una fecha de retroactividad. La aseguradora no responderá por las reclamaciones presentadas durante la vigencia del seguro que correspondan a hechos ocurridos antes de la fecha de retroactividad establecida.

En esta clase de seguro por reclamación se recomienda consignar expresamente en la póliza que los hechos o circunstancias conocidos y avisados a la aseguradora por el asegurado durante la vigencia del seguro que puedan dar lugar a una reclamación posterior de la víctima, se entienden como reclamaciones y en consecuencia son objeto de cobertura bajo la póliza. Es importante incluir esta nota debido a que la póliza que se suscriba para la siguiente vigencia excluirá de manera expresa de la responsabilidad derivada de hechos

5 Sentencia Corte Suprema de Justicia. Sala Penal. SP13285-2014Octubre $1^{\circ}$ de 2014. Radicación: 42256. Magistrado ponente: Fernando Alberto Castro Caballero.

6 Artículos 1127 y 1131 Código de Comercio. Artículo 4 Ley 389 de 1997. 
conocidos o avisados por el tomador o el asegurado con anterioridad al momento de celebrar el nuevo contrato. Con la previsión anterior, en el evento de que el damnificado formule su reclamación una vez finalizada la vigencia, el asegurado contará con la cobertura de la póliza.

Ocurrencia de cola corta (Reclamación especial, Sistema Mixto, Sunset): bajo esta modalidad de cobertura, la aseguradora cubre el valor de la indemnización que tenga que pagar el asegurado como consecuencia de la responsabilidad civil derivada de hechos ocurridos durante la vigencia del seguro, siempre que la reclamación de la víctima sea formulada al asegurado o a la aseguradora dentro de un periodo establecido en la póliza, el cual, conforme a lo previsto por el artículo 4 de la Ley 389 de 1997, no puede ser inferior a dos (2) años.

Esta modalidad de cobertura ofrece al asegurado un amparo más restringido, especialmente si se trata de responsabilidad civil extracontractual. En Colombia algunas aseguradoras han adoptado esta modalidad para sus pólizas de responsabilidad civil estableciendo que el plazo dentro del cual la víctima debe presentar la reclamación al asegurado o a la aseguradora es de dos años. En estos eventos el asegurado puede encontrarse desprotegido si la reclamación de responsabilidad civil es válidamente presentada por el damnificado una vez expirado el plazo establecido, tomando en consideración que para que el riesgo se entienda realizado, o lo que es lo mismo, para que se entienda ocurrido el siniestro, se requiere que se cumplan los dos supuestos: i) que el hecho ocurra durante la vigencia de la póliza y ii) que la reclamación de la víctima se presente dentro del plazo establecido. Si no se dan las dos circunstancias no puede hablarse de siniestro, ni existirá cobertura bajo la póliza pactada bajo esta modalidad de delimitación temporal.

5. Prescripción de las acciones del seguro en las tres modalidades de delimitación temporal de la cobertura

Hasta la expedición de la Ley 45 de 1990, cuando la única modalidad legalmente admisible en Colombia para las pólizas de responsabilidad civil era la de Ocurrencia Pura, se discutía si el cómputo de los términos de prescripción iniciaba con el acaecimiento del si- 
niestro, esto es, con la ocurrencia del hecho externo imputable al asegurado, y una vez transcurrido el tiempo legalmente previsto, la reclamación formulada por el asegurado en fecha posterior podía ser objetada válidamente por las aseguradoras alegando la prescripción. Tomando en consideración que, tratándose de reclamaciones derivadas de la responsabilidad civil extracontractual, en múltiples ocasiones el asegurado se quedaba sin cobertura porque la reclamación de la víctima se presentaba cuando ya había expirado el término de prescripción aplicable al contrato de seguro celebrado, pero aún no se había cumplido el término de prescripción correspondiente a la responsabilidad civil, se reformó mediante el artículo 84 de la Ley 45, el artículo 1131 del Código de Comercio, con el objeto de precisar sin lugar a dudas el momento a partir del cual deben computarse los términos de prescripción correspondientes a la acción directa y a la acción del asegurado contra el asegurador.

Aclarando este punto se pronunció la Corte Suprema de Justicia ${ }^{7}$ en sentencia que aludía al antiguo texto del artículo 1131 del Código de Comercio el siguiente sentido:

"5.- Si bien es cierto que la realización del riesgo asegurado, es decir, la ocurrencia del siniestro (art. 1.072 C. de Co.) autoriza al asegurado o al beneficiario en su caso a reclamar el pago de la suma asegurada a título de indemnización, no lo es menos que en los seguros de responsabilidad civil por expresa disposición del artículo 1.131 del Código de Comercio, según su redacción inicial, ella no puede exigirse al asegurador sino cuando el damnificado su causahabiente "demanden judicial o extrajudicialmente la indemnización"., norma vigente al momento de iniciarse este proceso, modificada después por el artículo 86 de la ley 45 de 1990. Pero tal disposición especial encuentra su razón en el riesgo asegurado y su ocurrencia. En efecto, en esta clase de seguros, de una parte, el riesgo asegurable es la responsabilidad contractual o extracontractual admitida por la ley. Pero, de la otra, la ocurrencia de este riesgo y la reclamación de la responsabilidad por el mismo suele desenvolverse en una serie sucesiva de hechos y actos en el tiempo, que, lo mínimo, la ley lo considera integrado por el hecho externo imputable al asegurado, por el establecimiento de la posibilidad de quedar cobijado un contrato

7 Sentencia Corte Suprema de Justicia. Sala de Casación Civil y Agraria. Mayo 18 de 1994. Expediente N4106. Magistrado ponente: Dr. Pedro Lafont Pianetta. 
de seguro dentro de la responsabilidad del asegurador y por la reclamación efectiva de la responsabilidad atribuida al asegurado con la consiguiente indemnización. De allí, que fuera necesario definir la importancia de cada uno de estos momentos, lo que hace el artículo 1.131 del Código de Comercio en la siguiente forma: el hecho externo imputable al asegurado es determinante para estimar estructurado y ocurrido el siniestro sin que se requiera actividad o hecho posterior alguno. En cambio, la segunda actividad de confrontación contractual está encaminada a establecer teóricamente la responsabilidad del asegurador frente al asegurado, teniendo en cuenta el contenido del contrato y sus limitaciones convencionales y legales (arts. 1127, 1055, 1128, 1229 y 1130 C.Co.). Pero el tercer hecho, el de la demanda judicial o extrajudicial de la indemnización de la víctima al asegurado, lo toma el citado precepto como hecho mínimo para la exigibilidad de la responsabilidad que puede reclamar el asegurado frente al asegurador. La ley no le exige al asegurado que primero sea declarado responsable para luego demandar la responsabilidad del asegurador; pero en cambio le exige por lo menos se le haya demandado la indemnización. Por ello perentoriamente se prescribe, en términos inequívocos, que dicha "responsabilidad... solo prodrá [sic] hacerse efectiva cuando el damnificado o sus causahabientes demanden judicial o extrajudicialmente la indemnización (Art. 1131 C.Co.) (Subraya la Sala). Luego si solo desde ese instante puede reclamarse la responsabilidad al asegurador por parte del asegurado, mal puede hacérsele el cómputo de la prescripción desde época anterior.

6.- Luego, resulta absolutamente claro que, sin que mediara "demanda judicial o extrajudicial", al asegurado le quedaba vedado el camino para reclamar al asegurador una indemnización a título del contrato de seguro, pues a él nadie la había reclamado todavía; y, precisamente por ello, ese asegurador podía entonces (artículo 1.131 C. de Co., citado), aducir que no le era exigible el cumplimiento de la obligación indemnizatoria derivada del contrato de seguro, pues por ministerio de la ley, la exigibilidad de la misma dependía no solo de la realización de un hecho externo imputable al asegurado y generador para este de responsabilidad civil, además requería la condición adicional de que este fuera objeto de "demanda, ya "judicial", ora "extrajudicial", criterio este de interpretación que finalmente, coincide con el nuevo texto del citado artículo 1.131 del C. de Co., en 
el cual se establece que en esta especie de seguros, la prescripción "frente al asegurado" tiene ocurrencia "cuando la víctima le formula la petición judicial o extrajudicial." 8

No obstante la Corte se refiere al artículo 1131 en su redacción anterior a la reforma de la Ley 45 de 1990, la Corte precisa la razón por la cual el término de la prescripción corre contra el asegurado únicamente a partir del momento en el que se le formula la petición judicial o extrajudicial por parte del damnificado o sus causahabientes, aclarando que este concepto es independiente del momento en el que se entiende ocurrido el siniestro. En consecuencia, ocurrido el siniestro, esto es, un hecho generador de un daño amparado, la póliza que resultará afectada será la que se encuentre vigente en el momento en el que acaezca el hecho externo imputable al asegurado, pero la prescripción de la acción del asegurado contra la aseguradora no correrá sino hasta tanto el damnificado le formule la petición judicial o extrajudicial correspondiente.

El actual artículo 1131 C. de C., norma que regula el tema de la prescripción tratándose del seguro de responsabilidad pactado bajo modalidad ocurrencia, establece: "En el seguro de responsabilidad se entenderá ocurrido el siniestro en el momento en que acaezca el hecho externo imputable al asegurado, fecha a partir de la cual correrá la prescripción respecto de la víctima. Frente al asegurado ello ocurrirá desde cuando la víctima le formula la petición judicial o extrajudicial."

Tomando en consideración que mediante la reforma introducida por la Ley 45 de 1990, se dotó a la víctima de acción directa para reclamar a la aseguradora la indemnización en los casos en que el causante del daño cuenta con un seguro de responsabilidad civil, el legislador aclara en el citado artículo 1131, que frente a la víctima el siniestro lo constituye el hecho externo imputable al asegurado, es decir el hecho dañoso, y es a partir de ese momento que corre la prescripción tratándose de la acción directa del damnificado contra la aseguradora.

Frente al asegurado, el siniestro se entiende también ocurrido cuando acaece el hecho externo imputable al asegurado, pero sólo hasta cuando el damnificado le formule la petición judicial o extrajudicial

8 Sentencia Corte Suprema de Justicia. Sala de Casación Civil y Agraria. Mayo 18 de 1994. Magistrado ponente: Pedro Lafont Pianetta. 
correrá la prescripción de la acción del asegurado frente a la aseguradora.

Bajo la modalidad de reclamación pura, es decir, cuando se estipula en el contrato que se amparan las reclamaciones formuladas por el damnificado al asegurado o a la compañía de seguros durante la vigencia de la póliza, con o sin retroactividad, los términos de prescripción empezarán a correr, con sujeción a lo establecido en el artículo 1081, a partir del momento de la reclamación de la víctima, que es el hecho que da base a la acción, tanto para la acción directa de la víctima como para la acción del asegurado contra la aseguradora.

Bajo la modalidad Mixta o Sunset, no será aplicable la regla prevista por el artículo 1131, que dispone que frente a la víctima se entenderá ocurrido el siniestro desde el momento en el que acaece el hecho externo imputable al asegurado y a partir de ese momento correrá la prescripción tratándose de la acción directa. Es a partir del momento en que acaece el hecho externo, que el damnificado puede dirigirse directamente contra la aseguradora para hacer efectivo su derecho, pero el siniestro sólo se entenderá ocurrido hasta tanto se presente la reclamación de la víctima a la aseguradora o al asegurado.

Respecto del asegurado en la modalidad Mixta o Sunset el siniestro se inicia con la ocurrencia del hecho externo, pero se encuentra en todo caso, sujeto a la condición de que la reclamación se presente dentro del plazo pactado para que surja la obligación a cargo de la aseguradora. En consecuencia, la prescripción tratándose de la acción del asegurado contra la aseguradora, correrá a partir de la reclamación del damnificado, siempre que ésta se presente dentro del término especial previa y expresamente establecido por las partes.

La consecuencia que se deriva de que la reclamación de la víctima se formule por fuera de dicho periodo pactado, será la inexistencia de cobertura, por tratarse de un hecho que no puede enmarcarse de manera completa dentro del concepto de riesgo amparado por el contrato de seguro correspondiente. La ocurrencia del hecho dañoso y la reclamación de la víctima se desenvuelven de manera sucesiva en el tiempo. Pero, en todos los casos la reclamación de la víctima, constituye el hecho determinante para que surja la obligación a cargo de la aseguradora. Sólo a partir de ese momento se entiende cumplida íntegramente la condición, es decir, totalmente realizado el riesgo, ocurrido el siniestro, y es entonces que puede exigirse 
a la aseguradora el cumplimiento de la obligación a su cargo. En consecuencia, la reclamación de la víctima determina el momento, a partir del cual debe hacerse el cómputo de la prescripción correspondiente.

Las dificultades señaladas en cuanto a la interrupción de la prescripción tratándose de la modalidad de ocurrencia, se encuentran también presentes tratándose de coberturas pactadas bajo la modalidad de Reclamación o Claims Made. En estos casos, los términos corren contra el asegurado a partir de la petición o reclamación judicial o extrajudicial que formule el damnificado. Entonces, al formular la víctima la reclamación "extrajudicial” empieza a correr el término de prescripción correspondiente. En el evento de que la reclamación "judicial" sea formulada una vez transcurridos los términos previstos en el artículo 1081, contados a partir de la reclamación extrajudicial, la aseguradora podrá válidamente proponer la excepción de prescripción, quedando el asegurado desprovisto de la cobertura del seguro.

6. Término de prescripción de la acción de responsabilidad civil extracontractual

En Colombia, conforme a lo dispuesto por el artículo 2536 del Código Civil, el término de prescripción aplicable para la acción de responsabilidad civil extracontractual es de diez (10) años.

En países como Chile (art. 2332 C.C.), Perú (art. 2001 C.C.), Argentina (art. 4037 C.C.), España (arts. 1902 y 1968 C.C.), Ecuador (art. 2259 C.C.), México (art. 1934 C.C.) los términos legalmente establecidos para la prescripción de la acción de responsabilidad civil extracontractual oscilan entre uno (1) y cuatro (4) años.

El término de diez (10) años establecido por la ley en Colombia para la acción de responsabilidad civil extracontractual tiene un impacto muy importante en lo que se refiere al seguro de responsabilidad civil suscrito tanto bajo modalidad ocurrencia, como bajo modalidad Mixta o Sunset.

Conforme a lo dispuesto por el artículo 1131 del Código de Comercio, el término de prescripción de la acción que tiene el asegurado contra la aseguradora empieza a correr sólo desde que la víctima del daño le formula la petición judicial o extrajudicial de indem- 
nización. En consecuencia, si la víctima dispone de diez años para ejercer la acción de responsabilidad civil extracontractual y solicitar al causante del deño la indemnización correspondiente, la obligación de la aseguradora que había expedido la póliza bajo modalidad ocurrencia vigente al momento de ocurrir el daño, puede ser exigida dentro de los dos (2) años siguientes a la formulación la petición por parte de la víctima.

Sobre este punto se pronunció el Consejo de Estado en sentencia de octubre 9 de 2014 en los siguientes términos:

"Ahora bien, la lectura del artículo 1081 de la ley mercantil, debe ser compaginada con las disposiciones del artículo 1.072 y 1.131 del Código de Comercio, lo que disponen:

ARTÍCULO 1.072.- Se denomina siniestro la realización del riesgo asegurado.

ARTÍCULO 1.131. En el seguro de responsabilidad se entenderá ocurrido el siniestro en el momento en que acaezca el hecho externo imputable al asegurado, fecha a partir de la cual correrá la prescripción respecto de la víctima. Frente al asegurado ello ocurrirá desde cuando la víctima le formula la petición judicial o extrajudicial. Una confrontación entre los artículos 1081 y 1131 del Código de Comercio evidencia que la segunda disposición guarda armonía con la primera, en tanto identifica el momento en el cual comienza a contarse los términos de prescripción de que trata el artículo 1081. En efecto, mientras el artículo 1081 señala que la prescripción ordinaria será de dos años para el interesado, el artículo 1131 precisa que dicho interesado puede ser el asegurado, a quien los términos de prescripción le comenzaran a correr cuando la víctima, esto es, la persona que sufrió el siniestro, le formula petición judicial o extrajudicial.

Sobre esto último, cabe decir que aunque la norma comercial no establece quienes pueden ser los interesados en las acciones derivadas del contrato de seguro, la Corte Suprema de Justicia, vía jurisprudencial, los ha identificado como "todos aquellos de quienes deriva algún derecho del contrato de seguro, que la tenor de los numerales primero y segundo del artículo 1047 son el tomador, el asegurado, el beneficiario y el asegurador. Estas son las mismas personas contra quienes pueden correr la prescripción extraordinaria, porque no se trata de una acción pública que pueda ejercitar cualquiera. Aquellas 
personas distintas de los interesados carecen de acción, pues el contrato de seguro es para ellos res Inter allios acta (sic.)". ${ }^{9}$

El artículo 1037 del Código de Comercio define al asegurador como la persona jurídica que asume los riesgos, debidamente autorizada para ello con arreglo a las leyes y reglamentos; al tomador, como la persona que, obrando por cuenta propia o ajena, traslada el riesgo; mientras que la doctrina identifica al asegurado "como el titular de un interés que, de verse afectado con un siniestro, puede sufrir un perjuicio patrimonial" $10 \mathrm{y}$ al beneficiario, como "la persona que tiene derecho a recibir la indemnización, aun cuando no necesariamente debe tener interés asegurable".

Una misma persona puede ser tomador, asegurado y beneficiario del contrato de seguro si en ella se dan todas las características propias de dichas cualidades ${ }^{11}$, y la prescripción variara en cada una de ellas de acuerdo al momento en que tuvieron conocimiento del hecho que da lugar a la acción, que en el caso del asegurado, se reitera, dichos términos comenzarán a correr cuando la víctima le formula la petición judicial o extrajudicial.

Para el caso de autos, se observa que si bien el hecho dañoso o siniestro tratándose de contrato de seguros- acaeció el 19 de marzo de 1996 (fecha en la cual el señor Pedro Manuel Mercado falleció luego de que en su humanidad cayera un alud de tierra en medio de las obras de construcción del puente "El Pepo"), las víctimas (familiares del occiso) solo le reclamaron al INVIAS el pago de la indemnización que les correspondía por los daños causados cuando interpusieron la demanda de reparación directa, la que le fue notificada al INVIAS el 3 de marzo de $1998^{12}$ (f. 41, c. ppal 1).

9 Corte suprema de justicia, Sala de Casación Civil, Sentencia del 16 de diciembre de 2005, Exp. No. 05001-3103-016-1999-00206-01, M. P. Jaime Alberto Arrubla Paucar.

10 ] LOPEZ BLANCO, Hernán Fabio Comentarios al Contrato de Seguro, sexta edición, Dupre Editores, Bogotá, 2014, P. 205-206.

11 LOPEZ BLANCO trae un ejemplo práctico en donde una misma persona puede ostentar las tres calidades: El propietario de una casa que contrata un seguro de incendio, es el tomador porque traslada el riesgo del incendio a la aseguradora, es el asegurado porque es el titular del interés asegurable y, el beneficiario porque tiene el derecho a que se le pague la indemnización, ibíd.

12 El oficio del 22 de abril de 1997 no se tiene en cuenta como fecha para la contabilización del término de prescripción de la acción derivada del contrato de seguro, toda vez que el mismo: i) INVIAS dio respuestas a un derecho de petición a una persona diferente a los aquí demandantes y ii) dicho derecho de petición respondía de manera general varias preguntas en torno a la construcción del puente "El Pepo" y aunque en el mismo se hizo referencia al accidente en el que perdió la vida el señor Pedro Manuel Mercado, en ningún momento la entidad respondía a una reclamación por el perjuicio causado. 
Así las cosas, solo a partir de la fecha en que el INVIAS tuvo conocimiento de la demanda en su contra, es que comenzaron a correr los términos de prescripción ordinaria de la acción derivada del contrato de seguro. ${ }^{13}$

En consecuencia, contados a partir del 3 de marzo de 1998, la entidad contada con dos años para acudir en forma oportuna ante la jurisdicción, los que, en principio, vencían el 3 de marzo de 2000. Ahora bien, como quiera que la entidad presentó el escrito de llamamiento en garantía el 18 de marzo de 1998 (f. 46-46, c. ppal 1), bajo la vigencia del Decreto 01 de 1986, es a partir de la presentación de aquel que se interrumpieron los términos de prescripción."14

Como dijimos, las pólizas de seguro de responsabilidad civil pueden expedirse bajo tres modalidades de delimitación temporal de cobertura. Las pólizas que se pactan bajo modalidad Mixta o Sunset presentan para el asegurado serias dificultades cuando se trata de responsabilidad civil extracontractual. El asegurado puede encontrarse desprovisto de la cobertura del seguro si la reclamación de responsabilidad civil es presentada por el damnificado una vez expirado el plazo establecido, que en las pólizas pactadas bajo esta modalidad es de dos años. Su obligación de responsabilidad civil frente a la víctima sigue siendo plenamente exigible, pero no contaría con la cobertura del seguro suscrito.

Esta modalidad de cobertura mixta o sunset, en principio no generaría inconvenientes en la medida en que, el término para que la víctima formule su reclamación de responsabilidad pactado en la póliza de seguro, coincida con el de prescripción de la acción de responsabilidad civil correspondiente. En Colombia, hasta tanto no se reduzca el término de prescripción de la acción de responsabilidad civil extracontractual, el seguro suscrito bajo esta modalidad resulta abiertamente inconveniente si lo que se busca es la protección patrimonial del asegurado causante del daño.

13 El Hecho de que el INVIAS hubiera podido tener conocimiento del siniestro el mismo día en que ocurrió, para el caso de autos, en ningún momento esto se traduce en que el término de prescripción comenzó a correr a partir de dicha fecha, pues solo hasta el momento en que los demandantes le hicieron la reclamación a la entidad, aquello tuvo conocimiento de la posible responsabilidad que le asistía en el daño ocasionado.

14 Sentencia. Consejo de Estado. Sala de lo Contencioso Administrativo. Sección Tercera Subsección B. Octubre 9 de 2014. Proceso N²3001233-1000-1997-08939-02 (26964). Consejero Ponente: Ramiro Pazos Guerrero 
7. Otorgamiento de la cobertura de RC Patronal en exceso de las prestaciones de la seguridad social

La jurisprudencia colombiana ha reconocido de manera reiterada el derecho de la víctima de un accidente de trabajo a recibir la pensión a cargo de la Aseguradora de Riesgos Laborales y adicionalmente a obtener del empleador responsable del accidente la indemnización plena de perjuicios.

Sustenta la Corte su tesis en el hecho de que estas dos formas de reparación tienen distinta finalidad, tomando en consideración que la que está a cargo de la Aseguradora de Riesgos Laborales "busca proteger de manera objetiva al afiliado o a sus causahabientes senalados en la ley, siendo de naturaleza prestacional perteneciente al Sistema de Seguridad Social Integral; mientras que la indemnización plena de que trata el artículo $216 \mathrm{del} \mathrm{C.} \mathrm{S.} \mathrm{del} \mathrm{T.,} \mathrm{persigue}$ la indemnización completa de los daños sufridos al producirse un accidente de trabajo por culpa del empleador, en la modalidad de subjetiva, el cual hace parte de un riesgo propio del régimen del Derecho Laboral." 15

Señala además que otra de las diferencias consiste en que el empleador "no le es dable como responsable directo del perjuicio descontar suma alguna de las prestaciones dinerarias pagadas por la entidades del sistema de seguridad social"',6 a menos que el empleador responsable por culpa haya sufragado gastos que le correspondían a estas entidades, porque lo cubierto por tales entidades de previsión social es el riesgo laboral propio de la denominada "responsabilidad objetiva del patrono" en la ocurrencia del accidente de trabajo o la enfermedad profesional, pero en ningún momento la responsabilidad derivada de la culpa del empleador, que es de naturaleza subjetiva.

Sin entrar a hacer consideraciones relacionadas con la naturaleza jurídica del aseguramiento de los riesgos laborales a través del sistema de seguridad social, y con el derecho que se reconoce a la víctima para recibir la pensión a cargo de la Aseguradora de Riesgos Labo-

15 Corte Suprema de Justicia. Sala de Casación Laboral. SL 887-2013. Radicación n 42433. Acta No. 33. Octubre 16 de 2013. Magistrado ponente: Carlos Ernesto Molina Monsalve

16 Corte Suprema de Justicia. Sala de Casación Laboral. SL 887-2013. Radicación n 42433. Acta No. 33. Octubre 16 de 2013. Magistrado ponente: Carlos Ernesto Molina Monsalve 
rales y adicionalmente a obtener del empleador responsable del accidente la indemnización plena de perjuicios, estimamos importante señalar las dificultades que se vienen presentando en lo tocante a las coberturas otorgadas por el sector asegurador colombiano para amparar la responsabilidad civil patronal.

En las condiciones generales de las pólizas de seguro de responsabilidad civil bajo las cuales se ampara la responsabilidad civil patronal en el mercado asegurador colombiano, se encuentra la estipulación que dice:

LA ASEGURADORA INDEMNIZARÁ LOS PERJUICIOS QUE TENGA QUE PAGAR EL ASEGURADO EN RAZÓN DE LA RESPONSABILIDAD CIVIL QUE LE SEA IMPUTABLE POR LOS ACCIDENTES DE TRABAJO QUE SUFRAN LOS EMPLEADOS A SU SERVICIO EN EL DESARROLLO DE ACTIVIDADES ASIGNADAS A ELLOS.

EL PRESENTE AMPARO OPERARÁ EN EXCESO DE LAS PRESTACIONES SOCIALES CONSIGNADAS EN EL CÓDIGO LABORAL O EN EL RÉGIMEN PROPIO DE LA SEGURIDAD SOCIAL, Y/O CUALQUIER OTRO SEGURO OBLIGATORIO QUE HAYA SIDO CONTRATADO O HAYA DEBIDO SER CONTRATADO PARA EL MISMO FIN. ${ }^{17}$

Como puede apreciarse con facilidad, ante la ocurrencia de un accidente de trabajo, la cobertura otorgada por la aseguradora solamente opera en exceso de lo correspondiente al régimen de seguridad social y de las prestaciones consignadas en el Código Laboral.

Tomando en consideración que el empleador responsable del perjuicio no puede descontar suma alguna de las prestaciones dinerarias pagadas por las entidades del sistema de seguridad social, ni las previstas en el Código laboral, si la cobertura del amparo de Responsabilidad Civil Patronal se otorga en exceso de dichas sumas, el asegurado tendrá a su cargo el valor total de la indemnización. En consecuencia, el amparo de responsabilidad civil patronal otorgado bajo las pólizas de seguro se convierte en una protección en la práctica, inexistente.

8. Exigencia de que el hecho generador del daño sea accidental, súbito e imprevisto

La exigencia contenida en las condiciones de las pólizas de seguro de responsabilidad civil en el sentido de que el hecho o acto generador del daño sea accidental súbito e imprevisto, deja fuera de la

17 La redacción de la cláusula varía en las distintas pólizas pero el alcance es el mismo en todas ellas. 
cobertura del seguro los hechos o actos de carácter culposo, tomando en consideración que la culpa o negligencia debe estar presente como factor de imputación para que haya responsabilidad civil, tal como lo ha señalado reiteradamente la jurisprudencia.

- Corte Suprema de Justicia. Sala Civil. Diciembre 18 de 2012. Exp: 76001-31-03-009-2006-00094-01. Magistrado ponente: Ariel Salazar Ramírez. Señala que la Responsabilidad Civil exige que haya imputación por dolo o culpa. En Colombia no estamos bajo un régimen de responsabilidad objetiva.

- Corte Suprema de Justicia. Sala Civil. Enero 21 de 2013. Exp; 1101-31-03-026-2002-00358-01. Magistrado ponente: Fernando Giraldo Gutiérrez. La Responsabilidad Civil exige la presencia de una conducta reprochable a título de dolo o culpa.

- Corte Suprema de Justicia. Sala Civil. Agosto 8 de 2013. Expediente: 11001-3103-003-2001-01402-01. Magistrado ponente: Ruth Marina Díaz Rueda. "Para la prosperidad de pretensiones derivadas de esa especie de "responsabilidad civil", la Sala ha iterado, entre otros, en el fallo sustitutivo de 16 de septiembre de 2011, exp.2005-00058, que para “(...) despachar favorablemente una pretensión de la mencionada naturaleza, en línea de principio, deben encontrarse acreditados en el proceso los siguientes elementos: una conducta humana, positiva o negativa, por regla general antijurídica; un daño o perjuicio, esto es, un detrimento, menoscabo o deterioro, que afecte bienes o intereses lícitos de la víctima, vinculados con su patrimonio, con los bienes de su personalidad, o con su esfera espiritual o afectiva; una relación de causalidad entre el daño sufrido por la víctima y la conducta de aquel a quien se imputa su producción o generación; $y$, finalmente, un factor o criterio de atribución de la responsabilidad, por regla general de carácter subjetivo (dolo o culpa) y excepcionalmente de naturaleza objetiva (v.gr. riesgo)". '”

9. Cláusula compromisoria o de arbitramento

Mediante la inclusión de la cláusula compromisoria o de arbitramento, las partes acuerdan que la solución de las discrepancias que surjan entre ellas, derivadas del contrato, serán resueltas por un tribunal de arbitramento constituido de conforme a lo establecido por las mismas partes, o en su defecto por la ley. Se ha señalado que la 
justicia arbitral como mecanismo alternativo de solución de conflictos, tiene la ventaja de permitir que las diferencias sean resueltas de manera más rápida que si se ventilan a través de la justicia ordinaria $\mathrm{y}$, adicionalmente, que sean juzgadas por personas expertas, especialmente calificadas en la materia. Tratándose del seguro de responsabilidad civil resulta conveniente poner de presente las dificultades que pueden presentarse:

En el caso de reclamación judicial:

Frente a la víctima que formula su reclamación de indemnización a la aseguradora mediante el ejercicio de la acción directa, la cláusula compromisoria es inoponible, tomando en consideración que no puede resultar obligatorio para ella un acuerdo en cuya celebración no participó. Ello vulneraría sus derechos consagrados y reconocidos por la ley.

Frente al asegurado se presentan dificultades de orden práctico. Cuando se presentan reclamaciones judiciales de la víctima que tienen origen en la responsabilidad civil, lo procedente es que el asegurado llame en garantía a la aseguradora para que en el evento de resultar condenado en el proceso, ésta responda frente al damnificado conforme a lo estipulado en el contrato de seguro celebrado. En este supuesto, de haberse pactado la cláusula compromisoria, la aseguradora podría oponerse al llamamiento en garantía alegando la falta de competencia del juez para conocer del asunto. De presentarse el caso de que el juez no acepte el llamamiento ${ }^{18}$, el asegurado se vería ante la necesidad de demandar a la aseguradora solicitando la convocatoria del tribunal de arbitramento, pidiendo que se profieran condenas condicionadas y acudiendo a la suspensión del proceso hasta donde ello resulte posible, con el fin de interrumpir los términos de prescripción que comenzaron a correr con la reclamación del damnificado. Idéntica situación se presenta si el asegurado no llama en garantía a la aseguradora en la oportunidad procesal correspondiente.

En el caso de reclamación extrajudicial:

De igual manera frente a la reclamación extrajudicial del damnificado, el asegurado se vería en la necesidad de iniciar el trámite de un

18 Ver: Consejo de Estado. Sección Tercera. Febrero 19 de 2004. Consejero ponente: María Helena Giraldo Gómez. Ref. N76001-23-31-000-2001-05524-01 (26048).

Consejo de Estado. Sección Tercera. Junio 10 de 2004. Consejero ponente: Ricardo Hoyos Duque. Ref. No76001-23-31-000-2001-02293-01 (25010). 
proceso arbitral contra la aseguradora incurriendo en costos innecesarios, con el fin de interrumpir la prescripción que viene corriendo desde el momento en que se formuló la petición extrajudicial de la víctima. Tomando en consideración que, una de las ventajas que tiene la justicia arbitral como mecanismo alternativo de solución de conflictos es la de permitir que las diferencias sean resueltas de manera más rápida, en este caso, la celeridad se vuelve en contra del asegurado debido a que, es muy probable que, el proceso arbitral contra la aseguradora termine antes de que se formule judicialmente la reclamación parte del damnificado.

10. Sublímites bajos en coberturas distintas del límite establecido para el amparo básico

Es usual el establecimiento de sublímites para los distintos amparos otorgados bajo las pólizas de seguro de responsabilidad civil. Los valores o sumas aseguradas para estos sublímites son inferiores, en la gran mayoría de los casos muy inferiores, a la suma asegurada establecida para el amparo básico otorgado bajo la misma póliza. Esta situación lleva a que el asegurado crea que la protección con que cuenta es la estipulada para el amparo básico, sin tomar en consideración las limitaciones que conllevan los sublímites al momento de establecer el valor de la indemnización a cargo de la aseguradora una vez acaecido el siniestro.

Este aspecto también presenta dificultades en los casos en que se toman coberturas en exceso, pues la diferencia que exista entre el sublímite de la póliza primaria y el mínimo asegurado en la póliza secundaria, termina representando un deducible adicional para el asegurado en los casos en que se afecten ambas pólizas.

11. Necesidad de probar la responsabilidad del asegurado en los casos en que la ley establece procedimientos especiales, cuando se ejerce la acción directa contra la aseguradora

Este aspecto genera inconvenientes para poder proceder a la determinación de la responsabilidad civil del asegurado, así como para establecer de manera cierta el valor de la indemnización a cargo de la aseguradora en los casos en que la reclamación se formula mediante el ejercicio de la acción directa. Se puede citar como ejemplo 
el caso de la responsabilidad de los directores y administradores para los que la ley establece un procedimiento especial que debe surtirse para la determinación de su responsabilidad frente a los socios o a la misma sociedad.

12. Gastos de defensa. Momento a partir del cual es exigible la obligación de la aseguradora

Los gastos de defensa y los gastos derivados del proceso instaurado por la víctima o sus causahabientes no se causan de manera inmediata con la formulación de la solicitud de indemnización por parte del damnificado. Se van causando en la medida en que se desarrolla el proceso de reclamación de la víctima. No es claro entonces el momento a partir del cual se debe iniciar el cómputo de los términos de prescripción correspondiente a la obligación de la aseguradora de pagar estos gastos, a cuyo pago tiene derecho el asegurado en virtud de la cobertura otorgada bajo la póliza de seguro de responsabilidad civil. Es frecuente encontrar en las pólizas que la cobertura de esos gastos se pacta bajo modalidad de reembolso, lo que permite concluir que, solamente hasta tanto el asegurado efectúe el pago de estos gastos será exigible el derecho frente a la aseguradora. En consecuencia, puede concluirse válidamente que en los casos en que se pacta la cobertura bajo modalidad de reembolso, el término de la prescripción correspondiente solo correría a partir del pago de los respectivos gastos por parte del asegurado.

\section{REFERENCIAS}

Artículos 1127 y 1131 Código de Comercio.

Artículo $4^{\circ}$ Ley 389 de 1997.

Ley 1480 de 2011

\section{SENTENCIAS}

Corte Suprema de Justicia. Sala Penal. SP13285-2014. Octubre 1 de 2014. Radicación: 42256. Magistrado ponente: Fernando Alberto Castro Caballero.

Corte Suprema de Justicia, Sala de Casación Civil, Sentencia del 16 de diciembre de 2005, Exp. No. 05001-3103-016-1999-00206-01, M. P. Jaime Alberto Arrubla Paucar. 
Corte Suprema de Justicia. Sala de Casación Laboral. SL 887-2013. Radicación $n^{\circ}$ 42433. Acta No. 33. Octubre 16 de 2013. Magistrado ponente: Carlos Ernesto Molina Monsalve.

Consejo de Estado. Sección Tercera. Febrero 19 de 2004. Consejero ponente: María Helena Giraldo Gómez. Ref. N76001-23-31-000-2001-05524-01 (26048).

Consejo de Estado. Sección Tercera. Junio 10 de 2004. Consejero ponente: Ricardo Hoyos Duque. Ref. N76001-23-31-000-2001-02293-01 (25010).

Sentencia Corte Suprema de Justicia. Sala de Casación Penal. SP13288-2014. Octubre $1^{\circ}$ de 2014. Radicación No.43575. magistrado ponente: Luis Guillermo Salazar Otero.

Sentencia Corte Suprema de Justicia. Sala Civil. Julio 5 de 2012. Ref. Exp. 050013103-008-2005-00425-01. Magistrado ponente: Fernando Giraldo Gutiérrez.

Sentencia Corte Suprema de Justicia. Sala Penal. SP13285-2014Octubre $1^{\circ}$ de 2014. Radicación: 42256. Magistrado ponente: Fernando Alberto Castro Caballero.

Sentencia Corte Suprema de Justicia. Sala de Casación Civil y Agraria. Mayo 18 de 1994. Expediente $N^{\circ} 4106$. Magistrado ponente: Dr. Pedro Lafont Pianetta.

Sentencia Corte Suprema de Justicia. Sala de Casación Civil y Agraria. Mayo 18 de 1994. Magistrado ponente: Pedro Lafont Pianetta.

Sentencia. Consejo de Estado. Sala de lo Contencioso Administrativo. Sección Tercera Subsección B. Octubre 9 de 2014. Proceso N²3001233-1000-1997-0893902 (26964). Consejero Ponente: Ramiro Pazos Guerrero

\section{LIBROS}

Lopez Blanco, Hernán Fabio Comentarios al Contrato de Seguro, sexta edición, Dupre Editores, Bogotá, 2014, P. 205-206. 